\title{
The Creation of Students' Academic Slang Expressions in the University of Botswana
}

\author{
Arua E. Arua/Modupe M. Alimi (Gaborone, Botswana)
}

\begin{abstract}
This study investigates the creation of students' academic slang expressions at the University of Botswana with data obtained from 32 items in a questionnaire consisting of 89 items. The semantic process of extension is the most widespread creative process, producing $101(66 \%)$ out of 153 selected slang expressions. Five morphological processes, compounding, derivation, conversion, acronymy and reduplication, together produce the remaining 52 (34\%) expressions. Also the process of semantic extension features in all aspects of the students' academic life in contrast with the other five morphological processes which are restricted. These findings show that the students draw extensively on and exploit the language resources at their disposal to create new meanings for describing their academic life. The findings also show that all the word formation processes highlighted relate to certain areas of the students' academic life, notably, the students' relationships with their lecturers, difficult courses and those who teach them, performances and grades.
\end{abstract}

\section{$1 \quad$ Introduction}

In an earlier study (2006), Alimi and Arua examined the role of slang in students' academic life at the University of Botswana (UB). One of the findings of the study is that students have a rich and extensive slang vocabulary for labelling various aspects of their academic life, specifically their class work, courses, academic performance, and their teachers and the manner in which they teach. According to the authors, the students employed "English, Setswana and creative combinations of the two in their descriptions" (2006: 110). They assert that the employment of both languages is "the logical outcome of a situation where both languages are in equal informal use" (ibid.). They then conclude that it is necessary to investigate, among other issues, the creativity exhibited by students (ibid.). The current study investigates the formation and structure of English language slang expressions at UB. The main questions it answers are: What are the semantic and morphological processes at work in the students' creative endeavour, and which of them are the most productive?

\section{$2 \quad$ Defining Slang}

Of recent, linguists have shown considerable interest in slang because of its prominence amongst youths, including college students. Though usually problematic to define, the literature available offers different perspectives on what constitutes slang. Dumas and Lighter (1978: 14-16), cited in Eble (1996: 12), outline four criteria for deciding whether a linguistic item constitutes slang. Their view is that a linguistic item will constitute slang if it fits two of the four criteria below: 
Its presence will markedly lower, at least for the moment, the dignity of formal or serious speech or writing; its use implies the user's special familiarity either with the referent or with the less statusful or less responsible class of people who have such special familiarity and use the term; it is a tabooed term in ordinary discourse with persons of higher social status or greater responsibility; it is used in place of the well-known conventional synonym [...].

The foregoing suggests that Dumas and Lighter (1978) are inclined to defining slang in terms of how they deviate from societal norms and attitudes.

Ellis (2002) defines slang as "a variety of language used in certain contexts by means of which people express their sense of belonging to a particular group within the community which is not specific to any geographic location." Eble (1996: 11) also defines slang "as an ever changing set of colloquial words and phrases that speakers use to establish or reinforce social identity or cohesiveness within a group or with a trend or fashion in society at large". Both Ellis and Eble focus on the social functions of slang, though the latter underscores one other important issue about slang terms, their short-lived nature. She observes that the vocabulary of college students depicts "the ephemeral and innovative character of slang" (1996: 13).

Martiello (2005: 15f.) defines slang by distinguishing the general from the specific. While general slang terms are used deliberately by speakers to break with the standard usage, and therefore are not group restricted, specific slang terms are used by people of common age and experience such as college students. They are therefore in-group markers. Hummon (1994: 77) defines college slang as "oral, informal highly expressive language that is created and used primarily as part of undergraduate life".

The definition adopted in this study is in line with that of Alimi and Arua. They discuss slang from the social function perspective as "the informal and highly expressive products of students' creativity which are used to describe their cultural, academic or social lives" (2008: 39). They observe, however, that though "some college slang terms exist in domains and settings outside the university campus, their meanings are not always accessible to the larger society" (Alimi/Arua 2006: 101). This view is also expressed in Eble's (1996: 26) assertion "that new slang words and expressions usually arise productively" with speakers drawing on the resources of the language, phonological, morphological and cultural, to express new meanings.

In terms of structure, it is now necessary to indicate what counts as a slang expression in this study. It is any descriptive label, actually rightly referred to as a lexical item, characteristic of the students. A lexical item includes traditional word forms (single words) and multi-words, including phrases, with single references (Halliday et al. 1964: 33). In the study, synonyms are treated as separate lexical items, just as they are in everyday language.

\section{Review of Literature}

A perusal of the literature shows that slang has been a subject considered worthy of attention by many scholars. Early research on the subject was mainly in the United States of America where the slang repertoire of students in many well known universities and colleges such as Harvard University (e.g. "College Slang Harvard"), Kansas University (e.g. "Kansas University Slang") and Stanford University (e.g. "Stanford Expressions") were examined (see, for example, R. G. B. 1889, Shidler 1932, Sebastian 1934, White 1955, Dundes/Schonhorn 1963, Underwood 1976). Recent research has followed a similar trend as the examples of Kings College, London (Thorne 2004, 2005) and North Carolina University (Eble 1989, 1996) show. 
Arua E. Arua/Modupe M. Alimi: The Creation of Students' Academic Slang Expressions

That slang is a prominent language variety is no longer contested. Fishman (1972: 166), for example, states that "in a very real sense, a language variety is an inventory of the concerns and interests of those who employ it at any given time". Allen (1983: 8), correlating types of nicknames with cultural influence and status in a society, demonstrates that the "vocabulary produced by past social situations offer information about those situations". It is also a pointer to the potential of "similar situations to produce similar results in any historical period and, by implication, in any society" (Allen 1983: 8). It is therefore expected that college students would regularly create new slang expressions to reflect and describe their academic life and other preoccupations.

Students create slang from a wide variety of issues. These include course names (Eschholz/Rosa 1970) and a host of others, such as absenteeism, grades, food items, behaviour of students and lecturers listed in Eble (1989) and Alimi and Arua (2006). They also use many strategies for the creation of the labels. In their study, Morgan, O'Neill and Harre (1979), cited in Allen (1983: 13), observe that the uses of personal nicknames (a type of slang, even in the larger society) among school children and the formation processes involved in the creation of the nicknames parallel those found among ethnic groups. According to these authors, one of the "etymological processes used by children in creating nicknames is internal formations including rhymes, contractions, verbal analogues, and suffix additions". Similar creative strategies, such as compounding, functional shift and shortening listed in Eble (1996: 26-35), apply to many slang words.

Studies by Thorne $(2004,2005)$ are examples of efforts to sustain a scholarly examination of slang. Thorne (2004), for example, examines students' slang terms in the United Kingdom and shows that some semantic clusters correlate with students' preoccupations. In a subsequent study, Thorne categorises slang terms amongst students in Kings College and various other higher institutions in the Greater London area. His findings confirm that slang terms are a reflection of "actual students' behaviour" (Thorne 2005: 4). In terms of their forms, he reports the presence of relexicalisation, overlexicalisation (cf. Halliday 1978), figures of speech and some word formation processes (2005: 4).

The most recent comprehensive scholarly examination of slang is found in Eble $(1989,1996)$. Eble (1989) focuses on the University of North Carolina slang repertoire. The importance of this treatment of slang is that it highlights the fact that slang is intricately woven into college students' academic and social life, a view that Alimi and Arua (2006, 2008) support. Eble (1996) is even more comprehensive, as it brings together the work that the scholar has done for more than a decade (for example, Eble 1984, 1990, 1991, 1994a, b). It shows that slang can be studied in multi-dimensional ways. Thus, in examining its formal and functional characteristics, she shows its relationship with grammar, morphology, lexicology, sociolinguistics, pragmatics, discourse analysis and other important fields of study. In so doing, she vigorously argues that slang is part of everybody's everyday life and that it is not confined to the hallowed walls of universities.

There have been few slang studies in ESL environments in Africa. These, however, follow a trend similar to their British and American counterparts: they are all studies of slang in university environments. Yusuf (1994) analyses two related slang expressions, "motherless babies" and "babiless mothers" amongst Nigerian University students. The structures of the two terms reveal the productive use of the -less suffix to denote two types of deprivation: "maternal care" in the first and "maternal joy" in the second. Goke-Pariola (1989) examines a collection of slang terms used by students of Obafemi Awolowo University in Nigeria. His findings reveal the following predominant themes: personal disposition, level of social sophistication, student or non-student status, course of study, reading habits, and level of industry. 
Alimi and Arua (2006), already mentioned, identify and discuss the labels with which students describe their academic life at UB. The labels reveal students' primary academic preoccupations: excellent and poor performance, good and poor teaching, difficult and easy courses, truancy, illegitimate relationships, cheating and passing and failing. The study also reveals a rich and extensive variety of students' labelling of various aspects of their academic life. In another study, Alimi and Arua (2008:51) investigate gender bias in the slang expressions that students at UB use to "describe female and male lecturers, on the one hand, and female and male students on the other, based on the sexual relationships they contract across teacher-student boundaries." Their findings show that in terms of endearing slang terms, female students and lecturers are discriminated against while both genders are treated alike in terms of disparaging slang expressions.

\section{$4 \quad$ Methodology}

There is now a tendency in sociolinguistic research to dismiss the questionnaire as a viable instrument for collecting data in favour of a corpus of naturally occurring language. As Biber, Conrad and Reppen (1998: 4) affirm, corpus based analysis is advantageous because "it is empirical, it analyses actual patterns of use in natural contexts, it makes extensive use of computers" and is capable of providing quantum information from "large and principled collection of natural texts". Unquestionably, corpus linguistics has provided new insights into language behaviour, and should be adopted as an analytical procedure when naturally occurring language is available.

The development of a corpus, however, is an expensive undertaking. In consequence, corpuses of particular varieties of language are yet to be developed. In such situations, researchers fall back on the questionnaire, which has, traditionally, been acknowledged to be a viable data collection instrument when properly used. In view of the lack of an English corpus in Botswana, although attempts are now being made to develop one, this study uses the data abstracted from items 1-32 in a questionnaire consisting of 89 items (see Appendix) that elicit information from some UB students on the descriptive labels they use for various academic issues, including their performance, their teachers and fellow students and the relationships they contract within and across teacher-student boundaries.

The data were collected from 163 third and fourth year students in the faculties of Business (33), Education (36), Engineering and Science (54), Humanities (33) and Social Sciences (7). These students were used because they were thought to have stayed long enough in the university to be familiar with most of the slang expressions they use to describe their academic and social life. The questionnaire was administered to five intact classes, one in each of the faculties mentioned. Some lecturers were approached and those who could release one hour of their teaching time administered the questionnaire in their classes. All improperly filled questionnaires and those in which the students answered very few questions were discarded, as it was thought that such questionnaires would distort the findings of the study. This accounts for the small number of respondents in the Faculty of Social Science.

Only 153 slang expressions out of a total of 691 elicited from the students have been used in this study. These are the English slang expressions considered to be unique to the UB environment. Accordingly, all the slang expressions already in common use or which have been imported from other climes are avoided. The method of data analysis is simple. Each of the 153 slang expressions is examined for the morphological or semantic process leading to its creation. As the meanings of the slang expressions have been extensively discussed in Alimi and Arua (2006), this aspect is not emphasized in this study. No complicated statistical procedures are employed since percentile scores adequately describe the data used in the study. The findings of the study are discussed below. 
Arua E. Arua/Modupe M. Alimi: The Creation of Students' Academic Slang Expressions

\section{Discussion of Findings}

Table 1 summarises the findings of the study:

\begin{tabular}{|l|r|r|}
\hline Creative process & Number of slang expressions & \% \\
\hline Semantic extension & 101 & 66.0 \\
\hline Compounding & 27 & 17.7 \\
\hline Conversion & 12 & 7.8 \\
\hline Derivation & 9 & 5.9 \\
\hline Acronymy & 2 & 1.3 \\
\hline Reduplication & 2 & 1.3 \\
\hline Total & 153 & 100.0 \\
\hline
\end{tabular}

Table 1: Semantic and morphological processes

As the Table shows, the creative process of semantic extension is the most widespread; it is used in the formation of 101 or $66.0 \%$ of the 153 slang expressions used in this study. As Crystal (1988: 40) and Crowley (1992: 152) indicate, the history of the English language shows that "thousands of words" have "undergone semantic broadening". The spread of the slang expressions, using Alimi and Arua's (2006) classification shown in Table 2, is instructive. It shows that the slang items formed through this creative process are used to describe every facet of the students' academic life. Extension is widely used because lexical items are readily available to be transformed to meet the peculiar needs of the students. Such items are obtained from a variety of sources including science, information technology, culture, religion and politics. 


\begin{tabular}{|c|c|c|c|}
\hline \multicolumn{3}{|c|}{ Category } & \multirow[t]{2}{*}{ Examples $(\mathrm{N}=101)$} \\
\hline 1 & Absenteeism & & \\
\hline 2 & Performance: & $\begin{array}{l}\text { Excellent students } \\
\text { Poor students }\end{array}$ & $\begin{array}{l}\text { toolbars, witches, wizards, hunk, prophets, antennae } \\
\text { learning disabled, puppets, corresponding students }\end{array}$ \\
\hline 3 & Studiousness: & $\begin{array}{l}\text { Not studious } \\
\text { Studious }\end{array}$ & $\begin{array}{l}\text { scientists, engineers } \\
\text { Ugandan, players, ancestors }\end{array}$ \\
\hline 4 & Courses: & $\begin{array}{l}\text { Difficult, and } \\
\text { Their teachers } \\
\text { Simple, and } \\
\text { Their teachers }\end{array}$ & $\begin{array}{l}\text { 102, PIN, riddles, organic, jail, hard core } \\
\text { dead woods } \\
\text { peaches, cream, Setswana, Humanities, GECs, slope, tea, } \\
\text { xmas, soft porridge, fat cakes } \\
\text { primary teachers, uneducated, boys and girls, } \\
\text { undergraduates, father xmas, kings, chief cook, chef, Mr, } \\
\text { Mistress, robots, Setswana teachers }\end{array}$ \\
\hline 5 & Grades: & $\begin{array}{l}\text { High } \\
\text { Average } \\
\text { Low }\end{array}$ & $\begin{array}{l}\text { clipper, heat, boiling point, ambassadors } \\
\text { border gate, body temperature, shoe sizes, square root, } \\
\text { room temperature, free way, bridge } \\
\text { red zone, titanic, under belt, sinkers }\end{array}$ \\
\hline 6 & Those who chea & & pilots, drivers \\
\hline 7 & Prolonged stude & tship & $\begin{array}{l}\text { genuine leather, senior citizens, vision 2016, Uganda, } \\
\text { ancestors, players }\end{array}$ \\
\hline 8 & Relationships: & $\begin{array}{l}\text { Female teachers } \\
\text { Male teachers } \\
\text { Female students } \\
\text { Male students }\end{array}$ & $\begin{array}{l}\text { rejects } \\
\text { plate no, retards, cradle snatchers, rapists, ghosts, snakes, } \\
\text { blood suckers, frogs } \\
\text { small houses, baby girls, hoes, bread winners, parasites } \\
\text { toy boys, baby boys, bibo, player, user, mama's boy, } \\
\text { puppets, hunk, user }\end{array}$ \\
\hline 9 & Lecturers: & $\begin{array}{l}\text { Competent } \\
\text { Incompetent }\end{array}$ & $\begin{array}{l}\text { computer, the messiah, professor, good pill, party maker } \\
\text { Mr, undergraduates, false prophet, bad pill }\end{array}$ \\
\hline
\end{tabular}

Table 2: Distribution of slang expressions formed through semantic extension

The meanings of the extended slang expressions may be transparent or opaque. Examples of the transparent ones include learning disabled - those who perform poorly and rapists - in particular, male lecturers who date female students. Examples of opaque slang expressions are square root - low grades and clipper - very high grades. All the examples in Table 2 are slang expressions derived from Standard British English lexical items. As the meanings of the four labels in this paragraph show, the expressions are characteristic of the students.

It should be noted that many of the slang expressions above are metaphorical. The metaphors involved are mainly those of food, death, age, religion and culture. Food metaphors are found in bibo - fruity drink, tea, fat cakes, soft porridge for the courses and chief cook and chef for the teachers. These are used connotatively for courses that are easy for the students or for the lecturers who teach them. The death metaphor is found in titanic, bad pill (incompetent lecturer) and sinkers, and these are used to connote failing grades and bad lecturers. Metaphors of religion include false prophets, messiah, Father Christmas and ancestors, all connoting good/bad lecturers and students who have overstayed their time on campus. The meaning content of these and other slang expressions is discussed extensively in Alimi and Arua (2006, 2008). 
Arua E. Arua/Modupe M. Alimi: The Creation of Students' Academic Slang Expressions

At 27 or $17.7 \%$ of 153 slang expressions, compounding is the next most productive creative process. The implication of this is that compounding and semantic extension constitute $84 \%$ of the processes by which the slang expressions at UB are formed. It should be noted that there is considerable overlap between extension and compounding. Generally, items that are extended are regarded, in this study, as those whose original literal meanings have been modified to fit the students' peculiar slang needs. Two items (genuine leather and boiling point) should suffice for illustrative purposes. The first is a tag usually attached to shoes in a departmental store to indicate that the shoes are of high quality. The second is a phrase usually used in a science class. Both of these phrases which exist in English have acquired peculiar meanings at UB. Genuine leather has both a negative and positive meaning. It refers to students who have stayed a long time on their programmes (negative meaning), but who are able to soldier on, in spite of this difficulty (positive meaning). Boiling point is the highest temperature at which a liquid boils. For students, this temperature is metaphorically equivalent to the highest grade. In other words, a student who scores very high marks has reached or is very close to boiling point.

Items that have been compounded are those that have been created from two word combinations of noun-nouns, adjective-nouns, verb-nouns and others. Although such combinations are found among the extended items, they do not have the force of new creations which the compounded items have. Again, two items (book snakes - those who are studious, and allowance eaters - those who are not) aptly illustrate this view. Both expressions are students' coinages.

Table 3 contains examples of the creative process of compounding and the areas in which they are most prominent.

\begin{tabular}{|c|c|c|c|}
\hline & \multicolumn{2}{|l|}{ Category } & Examples $(\mathbf{N}=27)$ \\
\hline 1 & \multicolumn{2}{|c|}{ Absenteeism (and absent students) } & clay cow, prospective ancestors, class auditors \\
\hline 2 & Performance: & Excellent students & $\begin{array}{l}\text { mega brains, naturally intelligents, hard core drivers, } \\
\text { natural cracks, suspect drivers }\end{array}$ \\
\hline 3 & \multicolumn{2}{|l|}{ Studiousness } & $\begin{array}{l}\text { book snakes, allowance eaters, suckman, carefrees, } \\
\text { resource abusers }\end{array}$ \\
\hline 4 & \multicolumn{2}{|c|}{$\begin{array}{l}\text { Difficult courses and their teachers } \\
\text { Simple courses and their teachers }\end{array}$} & $\begin{array}{l}\text { mega money suckers, option z, money suckers } \\
\text { free winners }\end{array}$ \\
\hline 5 & Grades: & $\begin{array}{l}\text { Average } \\
\text { Low }\end{array}$ & $\begin{array}{l}\text { binary marks } \\
\text { axe mark }\end{array}$ \\
\hline 8 & Relationships: & $\begin{array}{l}\text { Female teachers } \\
\text { Male teachers } \\
\text { Female students } \\
\text { Male students }\end{array}$ & $\begin{array}{l}\text { butter traders, sugar lecturers } \\
\text { stupid intellectuals, skirt chasers } \\
\text { marks campaigners, thigh for mark, mark suckers } \\
\text { cheese boys }\end{array}$ \\
\hline
\end{tabular}

Table 3: Slang expressions formed through compounding

Some areas of the students' academic life are more important than others if the word formation process of compounding were the sole criterion for determining students' and teachers' behaviour. The goings on between students and teachers are a major concern. As Alimi and Arua (2008) have shown, students do not support student-teacher relationships, and they use the most disparaging remarks to so indicate - stupid intellectuals - especially male lecturers who date female students and thigh for marks. Grades are also a major concern to 
students, especially when those grades are poor; hence, they are described as axe mark failing grades and binary marks - average marks. A related area deals with difficult courses. Teachers who teach such courses are referred to as mega money suckers because they make students repeat courses which they have to pay for. Other areas include absenteeism and excellent performance represented by the labels clay cow (part of the label is semantically extended) - those who absent themselves from classes, book snakes and allowance eaters. The competence or incompetence of teachers and prolonged studentship are among those areas that do not attract the attention of students in respect of compound slang expressions.

The morphological processes of conversion and derivation (12 or $7.8 \%$ and 9 or $5.9 \%$ respectively) rank next to compounding. Each of these processes is described and the areas in which they feature highlighted. Table 4 contains examples of both.

\begin{tabular}{|c|c|c|c|c|}
\hline & \multirow{2}{*}{\multicolumn{2}{|c|}{ Category }} & \multicolumn{2}{|c|}{ Examples } \\
\hline & & & Derivation $(N=9)$ & Conversion $(\mathrm{N}=12)$ \\
\hline 1 & Absent studen & & & don't cares \\
\hline 2 & Performance: & $\begin{array}{l}\text { Excellent students } \\
\text { Poor students }\end{array}$ & $\begin{array}{l}\text { solvists, solvers clay, } \\
\text { smarters, steppers } \\
\text { flunkers }\end{array}$ & stupids, retakes \\
\hline 3 & Studiousness & & book biters & don't cares \\
\hline 4 & $\begin{array}{l}\text { Difficult cour } \\
\text { Simple course }\end{array}$ & $\begin{array}{l}\text { and teachers } \\
\text { nd teachers }\end{array}$ & $\begin{array}{l}\text { non-deliverers, bridgers } \\
\text { spoon feeders }\end{array}$ & vicious, retakes \\
\hline 5 & Grades: & $\begin{array}{l}\text { High } \\
\text { Average }\end{array}$ & & $\begin{array}{l}\text { chopped } \\
\text { between }\end{array}$ \\
\hline 7 & Prolonged stu & tship & & matures \\
\hline 8 & Relationship: & $\begin{array}{l}\text { Female students } \\
\text { Male/female lecturers }\end{array}$ & & $\begin{array}{l}\text { prematures, for sale } \\
\text { stupids }\end{array}$ \\
\hline
\end{tabular}

Table 4: Slang expressions formed through the processes of conversion and derivation

In the case of conversion, the main pattern involves changing adjectives to nouns. Examples include: don't cares - those who do not study; stupids - male and female lecturers who have relationships with their students, and students who do not do well or those who are learning disabled (see discussion under extension); matures - those who have overstayed in the University and prematures - female students who are in relationships with their lecturers. Other patterns include changing verbs to nouns as in retakes - courses that students fail regularly, or students who do not do well, and prepositions to nouns as in between - average marks.

For derivation, one suffix, the -er agentive morpheme is used prominently. The morpheme is a deverbal nominalising suffix (Quirk et al. 1972: 993). It is added to such verbs as flunk, spoon feed and book bite (apparently arrived at through a process of compounding), bridge and step to produce nouns such as flunkers, spoon feeders, book biters, bridgers and steppers respectively. Unlike their Standard British English counterparts, these verbs do not exist separately in the students' slang repertoire. The -er morpheme can also be a de-adjectival nominalising suffix (Quirk et al. 1972: 993), as the example of smarters derived from smart (in consonance with the foregoing analysis where the words are derived from the roots) and -er shows. A less prominent morpheme is -ist. It performs a function similar to -er. However, there are very few examples of its use, the most prominent being solvists (students who are 
Arua E. Arua/Modupe M. Alimi: The Creation of Students' Academic Slang Expressions

capable of dealing with any academic problem, no matter how difficult). The rare occurrence of -ist may be due to the fact that its use involves "multiple affixation" (Katamba 1993: 52).

One interesting feature of the processes of conversion and derivation discussed above is the consistent occurrence of the $-s$ suffix. It should be noted that this suffix is inflectional not derivational. It merely performs the grammatical function of marking plurality. It shows that students refer to themselves in the plural; the subjects they name and the issues they describe affect them all.

The slang items formed through conversion and derivation support the discussion on compounding. Both of these processes provide slang items mainly in the areas of students' performance, their academic grades and the relationships they enter into with their lecturers, although in this case only female students are targeted. It is thus very clear that students worry about certain academic issues and form their slang expressions mainly around those issues. For a comprehensive discussion of these issues, see Alimi and Arua (2006).

Another interesting observation is that derivation, acknowledged in the literature on word formation processes to be one of the most productive (see Quirk et al. 1972: 993), is far less productive than compounding, and slightly less so for conversion in this study. One would have expected to see many affixes such as -ion, -ity, -ly and others being massively deployed in the formation of the slang expressions. It seems to be the case, however, that slang formation thrives more on the use of already existing lexical items. This would account for why the extension, compounding and conversion of already existing lexical items appear to be more important than the formation of entirely new slang expressions through derivation.

The last two slang formation processes discussed are acronymy ( 2 or $1.3 \%)$ and reduplication (also 2 or $1.3 \%$ ). Examples of acronymy, the formation of words using the first letters of words, are WOST - wasters of students' time and STM - sexually transmitted marks. There are two instances of reduplication in the data, year year - people who have stayed long on a course or in a programme and upon upon - excellent marks. However, the reduplication starts with the process of clipping - upon upon is a reduced version of 100 upon 100 or 10 upon 10 or of other marks to be scored. First, the numbers in the phrase are removed. Then, the item remaining after the process of clipping is repeated. In year year - year in year out, the prepositions are clipped leaving only the lexical items. Examples of these two processes are indeed few, although they still deal with some of the core issues already identified - performance and academic grades.

\section{Conclusion}

The study shows that two main word formation processes - semantic extension and compounding, in that order - account for the bulk (84\%) of UB students' unique slang vocabulary. Semantic extension is, predictably, the more productive of the two. Surprisingly, derivation, one of the most productive processes in other areas of language use, was not productive in this study. The result of this phenomenon is that the students used mainly existing English lexical items to form their slang expressions, a phenomenon which tallies with slang formation processes in the United States of America and the United Kingdom as Eble (1996) and Thorne (2005) have shown. Nevertheless, the researchers expected that slang derived from traditional morphemes such as -ion, etc. would have been widespread.

A second observation is that while semantic extension touches on all aspects of the students' academic lives as shown in Table 2, the other word formation processes do not. Taken together, though, all the word formation processes show that certain areas of the students' academic life are more talked about or more important than others. These important areas include the relationships that students contract with their lecturers, difficult courses and those 
who teach them, their performances and their grades, especially poor grades. Finally, the study has shown a picture of students' slang creativity in a southern African university. It may well be that the picture shown here is typical of other settings in Africa. There is thus need for further research not only in southern Africa, but in other settings in Africa to confirm the findings of this study.

\section{References}

Alimi, Modupe M./Arua, Arua E. (2008): "Gender and Student Slang in the University of Botswana". In: Arua, Arua E./Bagwasi, Mompoloki M./Sebina, Tiro/Seboni, Barolong (eds): English Language and Literature. Cross-Cultural Currents. New Castle: 38-53.

Alimi, Modupe M./Arua, Arua E. (2006): "Slang and Aspects of Students' Academic Culture at the University of Botswana". In: Arua, Alimi E./Bagwasi, Mompoloki M./Sebina, Tiro/Seboni, Barolong (eds.): The Study and Use of English in Africa. New Castle/Cambridge: $100-113$.

Allen, Irving L. (1983): The Language of Ethnic Conflict. Social Organization and Lexical Culture. New York.

Biber, Douglas/Conrad, Susan/Reppen, Randi (1998): Corpus Linguistics. Investigating Language Structure and Use. Cambridge.

Crowley, Terry (1992): An Introduction to Historical Linguistics. Oxford.

Crystal, David (1988): The English Language. London.

Dumas, B. K./Lighter, J. (1978): "Is Slang a Word for Linguists?" American Speech 53/1: 517. http://www.jstor.org/stable/455336?seq=10 (accessed September 11, 2008).

Dundes, Alan/Schonhorn, Manuel R. (1963): "Kansas University Slang. A New Generation". American Speech 38: 164-177.

Eble, Connie C. (1984): "Slang: Deviation or Norm?" In: Manning, Alan/Martin, Pierre M./ McCalla, Kim (eds.): The Tenth LACUS Forum, 1983. Columbia, S.C.: 409-416.

Eble, Connie C. (1989): College Slang 101. Georgetown, Conn.

Eble, Connie C. (1990): "College Slang in Conversational Structure". In: Jordan, Michael P. (ed.): The Sixteenth LACUS Forum, 1989. Lake Bluff, Ill.: 451-459.

Eble, Connie C. (1991): "Forms of Address in the Speech of College Students". In: Volpe, Angela della (ed.): The Seventeenth LACUS Forum, 1990. Lake Bluff, Ill.: 483-487.

Eble, Connie C. (1994a): "Lexicon and Culture: The Case of College Slang". In: Makkai, Valerie B. (ed.): The Twentieth LACUS Forum, 1993. Chapel Hill, N. C.: 601-607.

Eble, Connie C. (1994b): "Slang and Usage". In: Little, Greta D./Mongomery, Michael (eds.): Centennial Usage Studies. Tuscaloosa: 15-18. (= Publications of the American Dialect Society 77).

Eble, Connie C. (1996): Slang and Sociability. In-Group Language among College Students. Chapel Hill/London.

Ellis, Yvette (2002): "What is Slang?". Contemporary France Online. www.well.ac.uk/cfol/slang.asp (accessed September 11, 2008).

Eschholz, Paul A./Rosa, Alfred F. (1970): "Course Names. Another Aspect of College Slang". American Speech 45: 85-90.

Fishman, Joshua A. (1972): The Sociology of Language. Rowley, Mass.

Goke-Pariola, Abiodun (1989): "Language and Social Identity: Slang as Social Metaphor in a Nigerian University". Nigerian Journal of Sociolinguistics 2/2: 17-33.

Halliday, Michael A. K. (1978): Language as Social Semiotics. The Social Interpretation of Language and Meaning. London.

Halliday, Michael A. K./McIntosh, Angus/Strevens, Peter (1964): The Linguistic Sciences and Language Teaching. London.

Hummon, David M. (1994): "College Slang Revisited. Language, Culture and Undergraduate Life". The Journal of Higher Education 65/1: 75-98. 
Arua E. Arua/Modupe M. Alimi: The Creation of Students' Academic Slang Expressions

Katamba, Francis (1993): Morphology. Houndmills.

Martiello, E. (2005): "The Pervasiveness of Slang in Standard and Non-Standard English". Mots Palabras Words 6: 7-41. www.ledonline.it/mpw/allegati/mpw0506mattiello.pdf (accessed February 25, 2008).

Morgan, Jane/O'Neill, Christopher/Harré, Rom (1979): Nicknames. Their Origins and Social Consequences. London.

Quirk, Randolph/Greenbaum, Sidney/Leech, Geoffrey/Svartvik, Jan (1972): A Grammar of Contemporary English. London.

R. G. B. (1889): "College Slang, Harvard". American Notes and Queries 9, Nov., 22.

Sebastian, Hugh (1934): "Negro Slang in Lincoln University". American Speech 9: 287-290.

Shidler, John A. (1932): "More Stanford Expressions". American Speech 7: 434-437.

Thorne, Tony (2004): "Slang, Style-shifting and Sociability". www.kcl.ac.uk/content/1/c6/03/ 08/16/Slang,\%20Style-shifting\%20and\%20Sociability.doc (accessed April 29, 2006).

Thorne, Tony (2005): "Classifying Campus Slang". www.kcl.ac.uk/content/1/c6/03/08/16/ Classifying\%20Campus\%20Slang.doc (accessed April 29, 2006).

Underwood, Gary N. (1976): "Some Characteristics of Slang Used at the University of Arkansas at Fayetteville". Mid-South Folklore 4: 49-54.

White, William (1955): "Wayne University Slang". American Speech 30: 301-305.

Yusuf, Yisa Kehinde (1994): "From 'Motherless Babies' to 'Babiless Mothers'. A Sexist Metaphorical Transition of Female Undergraduates". Women and Language 17/2: 30-32. www.questia.com/PM.qst?a=o\&d=5000290440 (accessed April 29, 2006).

\section{Appendix}

Questionnaire on the Language Behaviour of UB Students

This questionnaire is designed to elicit (get) information on how UB students use language to interact amongst themselves. In other words, we are interested in the terms, names, labels and expressions (in English or Setswana) that you use to describe your (unique or peculiar) experiences.

We appreciate your taking out time to fill in the questionnaire.

Dr. M. M. Alimi Dr. A. E. Arua

\section{Section A}

What expressions are used to describe students who deliberately miss classes?

How do you describe the excuses such students give?

How do students describe those who perform excellently in their studies?

How do students describe those who perform poorly in their studies?

How do students describe those who perform well even when they do not make any serious effort to read?

How do you describe students who read excessively?

How do students describe those who are not serious with their studies?

How do you describe students who have spent much longer than they should in their academic careers?

How do you describe male students who date female lecturers?

How do you describe female students who date male lectures? 
How do you describe male lecturers who date female students?

How do you describe female lecturers who date male students?

How do you describe male students who date female lecturers for favour (marks, money, etc)?

How do you describe female students who date male lecturers for favour?

When classes are cancelled, how do students describe the cancellation?

What names do students give to class seminars and presentations?

What name do you give to a class/course with many students?

What names do you give to a class/course with few students?

What names do you give to courses that students fail regularly?

What names do you give to lecturers who teach courses that students fail regularly?

What names do you give to courses that students pass with little or no effort?

What names do you give to lecturers who teach such courses?

How do students describe very low marks in tests and exams?

How do students describe excellent marks?

How do students describe average marks?

How do you describe cheating in examinations/tests?

What names do you give to those who cheat in examinations or tests?

How do students refer to a lecturer who teaches well?

How do students refer to a lecturer who teaches poorly?

How do students refer to lecturers who are always punctual to class?

How do students refer to lecturers who are always late to class?

How do students refer to lecturers who never miss classes?

\section{Section B}

How do you describe male students who hold very strong religious views?

How do you describe female students who hold very strong religious views?

How do you describe the relationship between two female students who are excessively close?

What names do you give to such female students?

How do you describe the relationship between two male students who excessively with close?

What names do you give to such male students?

What word/words do you use for the relationship between opposite sexes (male or female)?

What name do you give to a male student who desires to go out with a female student who dislikes him?

What name do you give to a female student who desires to go out with a male student who dislikes her?

How do you describe a female student who dates a male student? 
Arua E. Arua/Modupe M. Alimi: The Creation of Students' Academic Slang Expressions

How do you describe a male student who dates a female student?

How do you describe male and female students who date each other and are in the same course/class?

How do you describe male and female students who date each other but are in different faculties/courses/classes?

How do you describe a man, not part of the university, who dates a female university student?

How do you describe a woman, not part of the university, who dates a male university student?

How do you describe a non-university girl who dates a male university student?

How do you describe a non-university boy who dates a female university student?

What words /expressions do you use for a very young female university student?

What words /expressions do you use for a very young male university student?

How do you describe a male student who is much older than his mates?

How do you describe a female student who is much older than her mates?

How do you describe a female student who neglects her studies in pursuit of much older men because they are rich?

How do you describe a male student who neglects his studies because he is involved in a relationship with a rich older woman?

How do you describe students who neglect their studies because of social activities such as parties?

How do you describe students who neglect their studies because they are engaged in money making businesses?

How do you describe students who are always busy with clan/club meetings to the detriment of their studies?

What names do you give to male students who hurt themselves and/or others physically if they are jilted (by their girlfriends)?

What names do you give to female students who hurt themselves and/or others physically if they are jilted by their boy friends?

What names do you give to male students who threaten to hurt themselves and/or others physically if they are rejected?

What names do you give to female students who threaten to hurt themselves and/or others physically if they are rejected?

\section{Section C}

What negative names do you use for leaders (president, vice president, ministers, and SRC members) who perform badly when they are in office?

What positive (endearing) names do you use to describe those of your leaders who perform very well when they are in office?

What names do you use for student leaders imposed on the student community by the university administration?

How do you describe confrontations with the University administration? 
How do you describe confrontations with the Ministry of Education?

How do you describe confrontations with the Police?

If there is a conflict within the student leadership, how do you describe such a conflict?

When you go on a procession to show your anger/dissatisfaction, what name do you give to the procession?

When you boycott the refectory, what name is given to the action?

How do you describe outside political interference in students affairs?

How do you describe lecture boycotts?

How do you refer to students' relationship with political parties?

\section{Section D}

When you are broke or you run out of money, how do you describe this?

What names do you give to students from poor homes?

What names do you give to students from rich homes?

What names do you give to modest/humble male students from rich homes?

What names do you give to modest/humble female students from rich homes?

What names do you give to rich male students who show off their wealth?

What names do you give to rich female students who show off their wealth?

How do you describe rich male students who are generous?

How do you describe rich female students who are generous?

How do you describe rich male students who are stingy?

How do you describe rich female students who are stingy?

What names do you give to your sponsors? (e.g. Ministry of Education)

How do you refer to organisations that support students financially, medically and socially?

How do you refer to students who withdraw from their studies for lack of funds?

\section{Section E}

Please list other student related activities, events, relationships which are not covered above and provide the labels for them. 